DOI: $\underline{10.7242 / 2658-705 X / 2019.2 .6}$

УДК 324

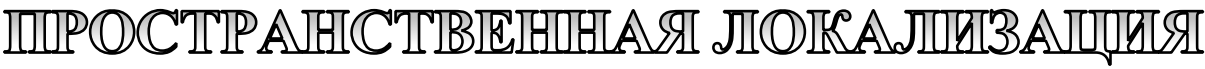

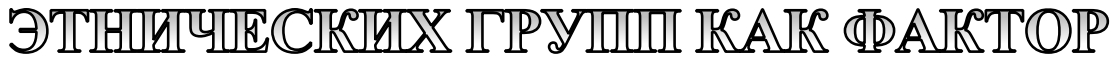

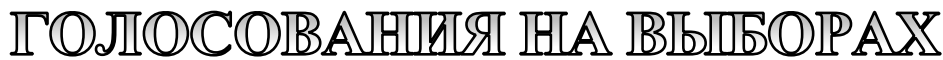

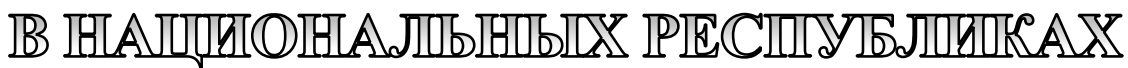

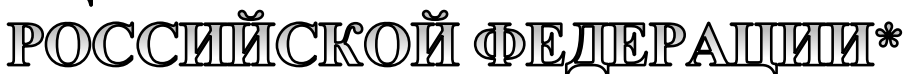

П.В. Панов, Пермский федеральный исследовательский центр УрО РАН

Хотя «национальные республики» выделяются в особую категорию субъектов РФ, они демонстрируют весьма высокую вариативность в голосовании на федеральных выборах. При этом лояльное по отношению к партии власти голосование связано не с «республиканским статусом» как таковым, a с этнической структурой населения республик, поскольку «этнические сети» являются важным ресурсом, который используется политическими машинами для электоральной мобилизации. Вместе с тем «этнические сети» - это не просто высокая доля представителей этнической группы в составе населения территории. Важным фактором, влияющим на формирование «этнических сетей», является фрормат пространственной локализации этнических групп. Когда члены этнической группы проживают «сегрегированно», то есть обособленно от представителей других этнических групп, возникает значительно больше шансов на то, что у них возникнут достаточно плотные социальные связи и интенсивные этнические идентичности, которые могут стать инструментом электоральной мобилизации. Эта гипотеза проверена на эмпирическом материале выборов Государственной Думы 2007, 2011 и 2016 гг. в национальных республиках. Анализ подтвердил, что сегрегированный формат пространственной локализации оказывает существенное влияние на эффеект воздействия доли титульной группы в составе населения национальных республик на голосование за Единую Россию.

Ключевые слова: национальные республики, выборы, этничность, титульная группа, пространственная локализация.

Исследователи российской субнациональной политики уже давно сделали вывод о специфике политических процессов в российских «национальных республиках» - этнических автономиях, к которым относятся 21 субъект РФ за исключением

Республики Крым, конституирование которой не имеет этнического характера [1]. Действительно, электоральные результаты показывают, что именно этнические республики демонстрируют повышенную лояльность на выборах в отношении «пар-

\footnotetext{
* Исследование выполнено при финансовой поддержке РФФИ, проект «Локализация этнических меньшинств в рамках политико-административных границ как фактор политизации этничности на субнациональном уровне: российские практики в контексте мирового опыта» № 19-011-00257 А.
} 
тии власти» и/или ее кандидатов. Это можно объяснить различными факторами. С одной стороны, политическая лояльность может быть существенным аргументом во взаимодействии с федеральным центром по поводу сохранения/предоставления неких преференций - материальных, институциональных, символических и т.д.

Конституционные преференции республик по сравнению с другими субъектами федерации довольно скромны (право принимать собственную конституцию и устанавливать свои государственные языки), но реальные практики взаимоотношений с центром и объемы автономии во внутренних делах складываются в процессе взаимодействий («торга») между акторами и варьируются достаточно широко. С другой стороны, принято считать, что в этнических республиках сложились специфические субнациональные политические режимы - более жесткие с точки зрения контроля правящих групп за политическими процессами, в том числе в электоральной сфере. Таким образом, республиканские элиты имеют и мотивации, и возможности для того, чтобы обеспечивать экстраординарные электоральные результаты партии власти и ее кандидатам.

Вместе с тем в эту логику вписываются далеко не все этнические республики, и в данной работе предпринята попытка уточнить ее по некоторым направлениям. Эмпирическим материалом являются результаты выборов Государственной Думы трех последних созывов - 2007, 2011 и 2016 гг. Более ранние выборы исключены из исследования в связи с тем, что именно к середине 2000-х гг. в стране сложился актуальный политический режим и партийная система с доминирующей партией. Выбор в пользу федеральных, а не региональных кампаний, обусловлен необходимостью использовать сопоставимые данные, тогда как выборы в субнациональные органы власти, очевидно, проходят в разном контексте. Наконец, выборы в Государственную Думу в данном случае предпочтительны по сравнению с президентскими кампаниями, поскольку президентские выборы в России намного более персонифицированы [9].

\section{Вариативность голосования в национальных республиках}

Прежде всего, необходимо обратить внимание на весьма высокую вариативность результатов выборов в этнических республиках. Учитывая, что все три анализируемые избирательные кампании (2007, 2011 и 2016 гг.) проходили в разных контекстах и вследствие этого дали партии власти - Единой России (ЕР) - различные результаты $(64,3 \%, 49,3 \%$ и $54,2 \%$ соответственно), доли голосов, которые ЕР получила в республиках, были взвешены общероссийскими результатами. Взвешенные, а также средневзвешенные для всех выборов значения представлены в табл. 1 .

Очевидно, что только половина республик (11 из 21) дают Единой России на выборах Государственной Думы результат, существенно (примерно на одну четверть) превышающий общероссийские показатели. При этом Калмыкия, Башкортостан и Северная Осетия в отдельные годы не достигали и этого значения, правда, партия власти все равно получала в этих регионах относительно больше голосов, чем по стране в целом. В то же время 6 республик демонстрируют прямо противоположные результаты, то есть стабильно голосуют менее лояльно по отношению к Единой России, чем страна в целом (небольшое исключение результаты ЕР в Бурятии в 2007 г.). Наконец, несколько республик - Алтай, Марий Эл и Коми - занимают промежуточное положение, здесь взвешенные значения колеблются около «0», то есть результаты партии власти примерно соответствуют общероссийским. К этой же группе относится и Адыгея, которая 
Таблица 1

Результаты Единой России на выборах Государственной Думы в «национальных республиках» 1

(отсортировано по убыванию средневзвешенных значений)

\begin{tabular}{|c|c|c|c|c|c|}
\hline $\begin{array}{c}\text { No } \\
\mathbf{n} / \mathbf{n}\end{array}$ & Республика & $\begin{array}{c}\text { EP 2007 } \\
\text { в3веш. }\end{array}$ & $\begin{array}{c}\text { EP 2011 } \\
\text { в3веш. }\end{array}$ & $\begin{array}{c}\text { EP 2016 } \\
\text { в3веш. }\end{array}$ & $\begin{array}{c}\text { EP } \\
\text { средневзвеш. }\end{array}$ \\
\hline 1 & Чечня & 1,5453 & 2,0170 & 1,7768 & 1,7797 \\
\hline 2 & Дагестан & 1,3871 & 1,8540 & 1,6402 & 1,6271 \\
\hline 3 & Мордовия & 1,4527 & 1,8577 & 1,5572 & 1,6225 \\
\hline 4 & Карачаево-Черкесия & 1,4448 & 1,8216 & 1,5074 & 1,5912 \\
\hline 5 & Ингушетия & 1,5353 & 1,8443 & 1,3360 & 1,5719 \\
\hline 6 & Тыва & 1,3841 & 1,7293 & 1,5240 & 1,5458 \\
\hline 7 & Кабардино-Балкария & 1,4949 & 1,6608 & 1,4338 & 1,5298 \\
\hline 8 & Татарстан & 1,2608 & 1,5781 & 1,5738 & 1,4709 \\
\hline 9 & Калмыкия & 1,1306 & 1,3402 & 1,3026 & 1,2578 \\
\hline 10 & Башкортостан & 1,2927 & 1,4294 & 1,0406 & 1,2542 \\
\hline 11 & Сев. Осетия-Алания & 1,1163 & 1,3767 & 1,2380 & 1,2437 \\
\hline 12 & Адыгея & 1,1037 & 1,2208 & 1,0969 & 1,1405 \\
\hline 13 & Алтай & 1,0802 & 1,0813 & 0,9006 & 1,0207 \\
\hline 14 & Мари Эл & 1,0504 & 1,0592 & 0,8616 & 0,9904 \\
\hline 15 & Коми & 0,9652 & 1,1924 & 0,6974 & 0,9517 \\
\hline 16 & Якутия & 0,9952 & 0,9968 & 0,8561 & 0,9493 \\
\hline 17 & Бурятия & 1,0201 & 0,9939 & 0,7996 & 0,9379 \\
\hline 18 & Удмуртия & 0,9420 & 0,9142 & 0,9317 & 0,9293 \\
\hline 19 & Чувашия & 0,9684 & 0,8804 & 0,9391 & 0,9293 \\
\hline 20 & Хакасия & 0,9258 & 0,8137 & 0,7030 & 0,8141 \\
\hline 21 & Карелия & 0,8908 & 0,6541 & 0,6882 & 0,7444 \\
\hline
\end{tabular}

голосует несколько более лояльно, эффективная работа политических но все же не настолько, как первая группа. машин позволяет партии $\quad$ власти

Эти данные еще раз подтверждают, получать высокие результаты в «нациочто лояльное голосование за партию нальных республиках».

власти практически не связано со статусом «национальной республики». Как известно, есть и несколько «русских регионов», где Единая Россия также получает экстраординарные результаты. Самый яркий пример, конечно, Кемеровская область, в меньшей мере - Краснодарский край, Ростовская, Пензенская, Саратовская области [8]. Следовательно, не сам по себе статус, а скорее

\section{Факторы эффективности политических машин}

Концепция политических машин $[10,11]$, которые обеспечивают электоральную мобилизацию, используя различные инструменты - административное давление, партикуляристское распределение различных материальных благ в обмен на голосование за партию власти и др.,

\footnotetext{
${ }^{1}$ Рассчитано по: Официальный сайт Центральной избирательной комиссии Российской Федерации. Информация о выборах и референдумах [Электронный ресурс] URL: http://www.vybory.izbirkom.ru/ (дата обращения: 25.03.2019).
} 
получила широкое распространение в изучении российской политики $[5,6]$. Исследователи указывают, что для эффективной работы политических машин, помимо прочего, требуются плотные социальные сети, через которые можно контролировать процесс голосования и поведение избирателей. Несмотря на то что, как показали Т. Фрай, Дж. Рейтер и Д. Сзаконии, политические машины могут успешно работать на «рабочем месте», в том числе в больших организациях и предприятиях [4], статистически подтверждается предположение о том, что для эффективной работы политических машин благоприятны более традиционалистские по своей природе сообщества [7]. В них плотнее и насыщеннее социальные связи, более значимы традиционные иерархии, труднее сохранить анонимность и, наоборот, проще обеспечить принуждение и/или контроль над голосованием. Наряду с так называемыми «тотальными учреждениями» (закрытые учебные заведения, военные части, дома престарелых и т.п.) и сельскими поселениями, к такого рода социальным группам относятся этнические сообщества, в которых этнические (традиционалистские по своей природе) идентичности и солидарности достаточно интенсивны. Поскольку этнические социальные связи значительно сильнее среди этнических меньшинств, чем среди доминирующей в стране - «нациообразующей» или «государствообразующей» [подробнее см.: 1, с. 24] группы населения, этнические меньшинства также являются благоприятной средой для работы политических машин.

Вместе с тем можно предположить, что высокая доля титульной этнической группы в составе населения помогает работе политических машин не всегда, а лишь в тех случаях, когда представители титульной группы проживают компактно, то есть географически локализованы и сконцентрированы на определенной территории, так сказать, выделены (отделены) из других этнических групп. Именно в этом случае, при прочих равных условиях, возникают плотные «этнические социальные сети». Действительно, вряд ли такого рода сети могут быть сильны, например, в городах, где население перемешано и намного более мобильно. Да и в сельской местности для политических машин, если речь идет о работе с «этническими сетями», для успеха предпочтительнее этнически гомогенное население.

Таким образом, значимыми факторами, влияющими на эффективность работы политических машин и, следовательно, на вариативность в голосовании за Единую России в «национальных республиках», являются доля сельского населения и доля этнических меньшинств (нерусского населения), а также представителей «титульной национальности» в составе населения республики. Дополнительно к этому в анализ включен такой социально-экономический показатель, как доля трансфертов из федерального бюджета в республиканском бюджете ${ }^{2}$. Гипотетически зависимость республики от федерального центра должна способствовать более лояльному голосованию.

Что касается фактора локализации титульных этнических групп, для его учета необходимо определить, как географически соотносятся ареалы проживания титульной этнической группы и других этнических групп, проживающих в республике. В общем плане можно выделить два формата локализации этнических

\footnotetext{
2 Для анализа использовались официальные данные, извлеченные из результатов Всероссийской переписи населения 2010 г. и ежегодных сборников, издаваемых Федеральной службой государственной статистики РФ. Поскольку зависимая переменная - средневзвешенное значение голосования за Единую Россию за три цикла, доля трансфертов рассчитана как среднее значение данного показателя (доля безвозмездных перечислений из федерального бюджета в республиканском бюджете) за несколько лет: 2010-2016 гг.
} 
групп относительно друг друга: 1) «сегрегированный» - когда этнические группы проживают в разных частях некой территории, то есть обособленно друг от друга; 2) «совпадающий» - когда они «смешаны», занимают одну и ту же территорию. Анализ пространственных характеристик титульных этнических групп выполнен Э.Ю. Минаевой [3] на основе комбинации двух баз данных: Geo-referencing of ethnic groups (GREG) и Geo-referencing Ethnic Power Relations (GeoEPR) $[12,13]^{3}$. Bce этнические группы в этих базах имеют географическую привязку, благодаря чему они представляют собой полигональные объекты (полигоны), накладывающиеся разными слоями друг на друга. Используя программу ArcGIS, на эти слои были наложены географически привязанные данные по границам субъектов РФ, которые содержатся в базе Global Administrative Areas (GADM).

В результате показатель «формат локализации» закодирован на порядковом уровне и принимает значения от «1» до «3». Минимальное значение («1») присваивается в том случае, если на территории республики полигон титульной этнической группы полностью или преимущественно (более половины полигона) совпадает с полигоном/полигонами другой/других этнических групп. Максимальное значение («3») дается, когда, наоборот, полигон титульной этнической группы полностью отделен (сегрегирован) от полигонов других этнических групп на территории республики. Значение «2» - большая часть полигона этнической группы сегрегирована, т.е. не совпадает с полигоном/полигонами другой/других этнических групп.

Например, полигоны адыгейцев в Адыгее, марийцев в Марий Эл, удмуртов в Удмуртии и т.д. (значение «1») расположены на картах GREG и GeoEPR так, что полностью перекрываются с соответствующими полигонами русских, а полигоны татар в Татарстане, бурятов в Бурятии и т.д. (значение «3»), напротив, полностью «сегрегированы» от полигонов всех других групп. Разумеется, локализация этнических групп в базах GREG и GeoEPR зафиксирована приблизительно и в значительной мере основывается на историческом расселении этнических групп так называемые «этнические территории» [2, с. 92-93]. Это, очевидно, не вполне совпадает с текущим распределением этнических групп по территории регионов, однако поскольку иных систематизированных геопривязанных данных пока не создано, остается полагаться на GREG и GeoEPR, имея в виду данное ограничение.

Анализ факторов, влияющих на эффективность работы политических машин, проводился методом линейной регрессии, результаты представлены в табл. 2. Зависимая переменная - «Голосование за ЕР»- средневзвешенная для выборов 2007, 2011 и 2016 гг. доля голосов, которые ЕР получила в республиках.

В Модели 1 и 2 включены соответственно доли «титульной группы» и русских в составе населения. В обоих случаях именно эти переменные оказываются единственными, которые имеют высокие и статистически значимые коэффициенты. Как и следовало ожидать, значения коэффициентов у этих переменных практически одинаковые, так как в большинстве случаев размеры этнических меньшинств и титульного населения почти совпадают. Поэтому в дальнейшем анализе переменная доля русских не использовалась.

Следует отметить, что ни доля сельского населения, ни доля трансфертов не явля-

\footnotetext{
${ }^{3}$ Обе базы были разработаны на основе созданного еще в 1964 г. советскими этнографами и уникального в своем роде «Атласа народов мира», который содержит карты расселения этнических групп. С помощью ГИС-технологий и с некоторыми уточнениями Атлас был трансформирован в современные базы геопривязанных данных.
} 
Таблищуа 2

\begin{tabular}{|c|c|c|c|c|c|}
\hline \multirow[b]{2}{*}{ Показатели } & Modol1 & Modol ? & Modol 2 & Modola & Mede 5 \\
\hline & (St.Er.) & $\begin{array}{c}\text { Est } \\
\text { (St.Er.) }\end{array}$ & $\begin{array}{l}\text { Est } \\
\text { ( St.Er.) }\end{array}$ & $\begin{array}{c}\text { Est } \\
\text { ( St.Er.) }\end{array}$ & $\begin{array}{c}\text { Est } \\
\text { ( St.Er.) }\end{array}$ \\
\hline Constant & $\begin{array}{l}1,014^{* \star *} \\
(0,601)\end{array}$ & $\begin{array}{l}1,461^{* *} \\
(0,022)\end{array}$ & $\begin{array}{c}0,996 \\
(0,634)\end{array}$ & $\begin{array}{l}1,639^{* *} \\
(0,656)\end{array}$ & $\begin{array}{l}1,479^{* * *} \\
(0,334)\end{array}$ \\
\hline Доля титульных групп & $\begin{array}{l}0,830^{\text {**** }} \\
(0,287)\end{array}$ & - & $\begin{array}{l}0,828^{* *} \\
(0,296)\end{array}$ & $\begin{array}{l}-0,842 \\
(0,853)\end{array}$ & $\begin{array}{l}-0,851 \\
(0,802)\end{array}$ \\
\hline Доля русских & - & $\begin{array}{c}-0,830^{* * *} \\
(0,264)\end{array}$ & - & - & - \\
\hline Формат локализации & - & - & $\begin{array}{l}-0,009 \\
(0,071)\end{array}$ & $\begin{array}{l}-0,275^{*} \\
(0,144)\end{array}$ & $\begin{array}{l}-0,282^{* *} \\
(0,134)\end{array}$ \\
\hline Доля сельского населения & $\begin{array}{c}0,338 \\
(0,716)\end{array}$ & $\begin{array}{c}0,031 \\
(0,681)\end{array}$ & $\begin{array}{c}0,303 \\
(0,787)\end{array}$ & $\begin{array}{c}0,246 \\
(0,717)\end{array}$ & - \\
\hline Доля трансфрертов & $\begin{array}{l}-0,008 \\
(0,557)\end{array}$ & $\begin{array}{c}0,258 \\
(0,486)\end{array}$ & $\begin{array}{c}0,034 \\
(0,658)\end{array}$ & $\begin{array}{l}-0,033 \\
(0,601)\end{array}$ & - \\
\hline Доля тит х Формат лок & - & - & - & $\begin{array}{c}0,644^{*} \\
(0,312)\end{array}$ & $\begin{array}{l}0,666^{* *} \\
(0,292)\end{array}$ \\
\hline Скор. R-square & 0,513 & 0,540 & 0,483 & 0,678 & 0,615 \\
\hline $\mathrm{N}$ & 21 & 21 & 21 & 21 & 21 \\
\hline Стат. значимость & & ${ }^{*} p<0$ & $0<0,05$ & $0<0,01$ & \\
\hline
\end{tabular}

ются значимыми предикторами. Доля сельского населения, правда, стабильно имеет положительный коэффициент, что соответствует ожиданиям. Кроме того, следует учитывать, что низкие значения регрессионных коэффициентов могут быть вызваны небольшим количеством случаев (21). Тем не менее, можно делать вывод о том, что в национальных республиках «этнические сети» имеют большее значение для успешной работы политических машин, нежели «сельские сети» (рисунок).

Значимость доли титульной группы в составе населения как фактора голосования за ЕР ярко проявляется на рисунке (нумерация случаев совпадает с нумерацией в табл. 1). Мы видим очевидную линейную связь между двумя переменными, причем все случаи вписываются в 95\%-ный доверительный интервал (две республики, правда, находятся на границе: Мордовия (3) и Чувашия (19)).

Мы, однако исходим из комплексной гипотезы, что доля титульной группы влияет на эффективность политических машин не сама по себе, а при условии сегрегированного формата локализации титульной группы на территории республики. Иначе говоря, следует выявить инте- рактивный эффект, а именно в какой мере переменная «Формат локализации» влияет на силу эффекта переменной «Доля титульной группы» на «Голосование за ЕР».

Следует заметить, что гипотеза о значимости формата локализации имеет под собой эмпирические основания: коэффициент корреляции между переменными «Формат локализации» и «Голосование за ЕР» позитивный, хотя и статистически незначимый. При этом если включить «Формат локализации» в регрессионное уравнение как отдельную переменную (Модель 3), ее коэффициенты оказываются статистически незначимы и даже имеют отрицательный знак. Однако, поскольку нас интересует не изолированное влияние формата локализации, а интерактивный эффект, в Модель 4 включена интерактивная переменная «Доля тит $x$ Формат лок».

Результат анализа подтверждает ожидания: при гипотетическом значении переменой «Формат локализации», равном «0» (в нашем случае этого нет) эффект доли титульных групп теряет статистическую значимость, а значение коэффициента «Доля титульных групп» даже становится отрицательным. В то же время позитивное и статистически значимое значение коэффици- 


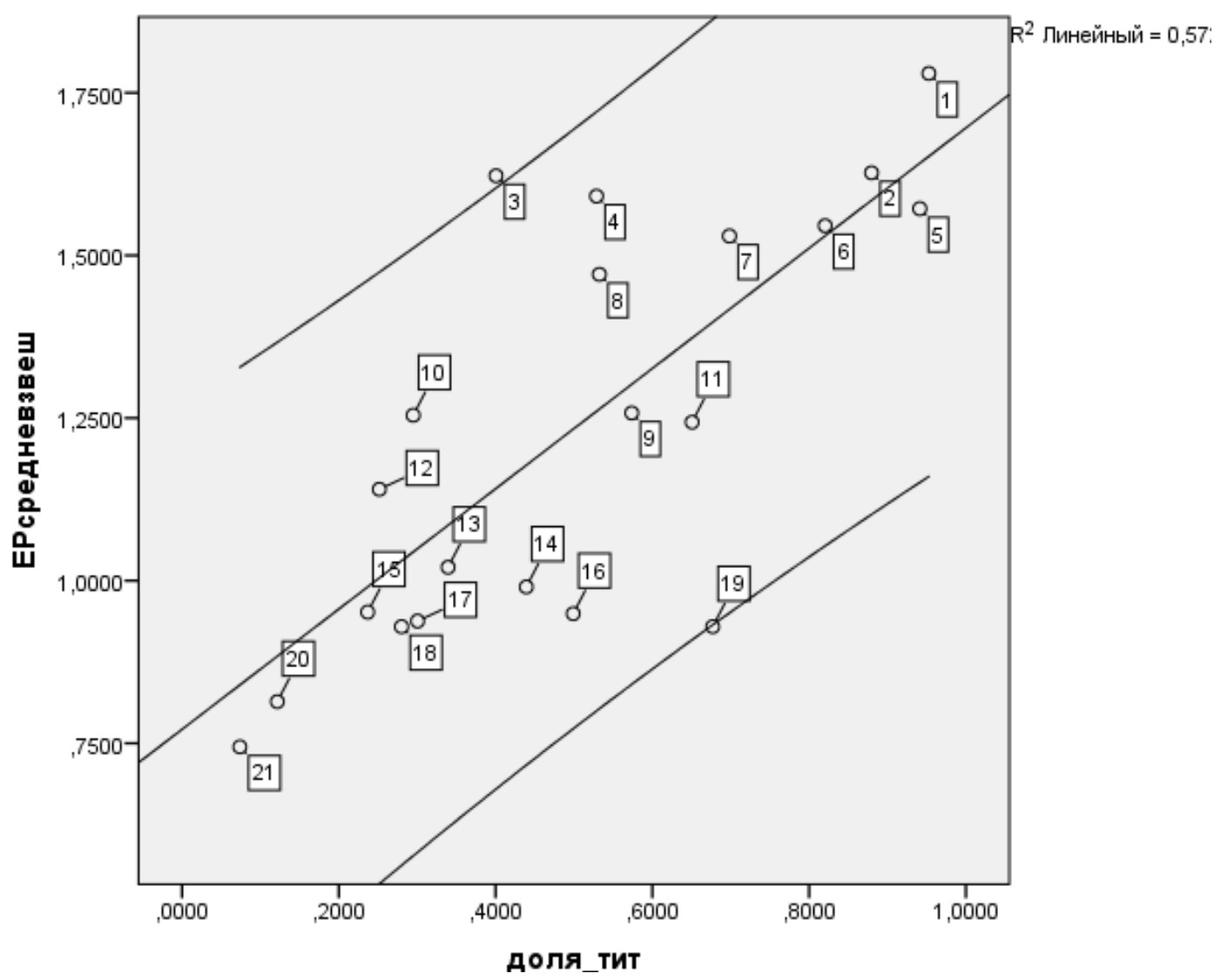

Рис. Соотномение значений переменных «Доля титульной группы» и «Голосование за Единую Россию»

ента интерактивной переменной говорит о том, что сила воздействия «Доля титульных групп» на голосование за Единую России существенно увеличивается по мере того, как титульная группа локализована в более сегрегированном формате. Каждое увеличение значения переменной «Формат локализации» на 1 дает увеличение силы воздействия «Доля титульных групп» на «Голосование за ЕР» на 0,644. Кроме того, резко возрастает объяснительная сила модели в целом (скорректированный $\mathrm{R}$-square достигает значения 0,678). Полученная картина сохраняется и в том случае, если исключить из анализа не имеющие статистической значимости переменные «Доля сельского населения» и «Доля трансфертов» (Модель 5).

\section{Локализация на субрегиональном уровне: Татарстан и Башкортостан}

Дополнительное подтверждение полученным результатам мы находим, если «спуститься» на субрегиональный уровень и проанализировать голосование за Единую Россию на тех же выборах в разрезе муниципальных образований (MO). Это возможно сделать применительно к таким типам МО, как городские округа (ГО) и муниципальные районы (MP), так как территориальные избирательные комиссии, в разрезе которых имеется электоральная статистика, как правило, создаются в рамках ГО и МР.

Следует иметь в виду, что из-за специфики политических процессов в разных республиках объединение данных по всем МО всех национальных республик в единый массив потребовало бы привлечения дополнительных инструментов многоуровневого анализа. В данном случае в этом нет необходимости, так как среди 21 республики обнаруживаются два региона (Татарстан и Башкортостан), сравнение которых позволяет в достаточной мере выявить эффект локализации ти- 
тульных групп на голосование за Единую Россию. Анализ геопривязанных данных в разрезе муниципальных образований показывает, что в Татарстане титульная группа (татары) практически всегда локализована в «сегрегированном формате», тогда как башкиры в Башкортостане, наоборот, в «совпадающем».

Таким образом, по интересующему нас фактору две республики демонстрируют наибольшие отличия, тогда как по всем остальным факторам они, напротив, достаточно сходны. Прежде всего, оба региона относятся к первой группе республик, демонстрирующих повышенную лояльность партии власти (см. табл. 1). Иначе говоря, политические машины здесь работают достаточно эффективно, хотя в Башкортостане в 2010-е гг. их эффективность несколько снизилась в связи в тем, что смена руководства республики (в отличие от Татарстана) прошла не в формате «преемника», что вызвало некоторое напряжение в региональной элите. Кроме того, обе республики достаточно развиты в социально-экономическом плане, имеют сходную структуру городского и сельского населения, а также сопоставимые значения населения и территории. Последнее также имеет значение, поскольку для количественного анализа необходимо достаточное количество ГО и МР. В Башкортостане их 63, в Татарстане - 45 .

Для выявления взаимосвязи между двумя ключевыми факторами (доля сельского населения в МО и доля титульной группы в составе населения МО) и голосованием за ЕР (взвешивалось общерегиональными значениями) проведен корреляционный анализ, результаты которого представлены в табл. 3.

Мы видим, что в Татарстане между долей титульной группы и голосованием за Единую Россию наблюдается достаточно высокая и статистически значимая корреляция. Обращает на себя внимание стабильность значений корреляционных
Таблийа 3

Результаты корреляционного анализа

\begin{tabular}{|c|c|c|c|c|}
\hline $\begin{array}{c}\text { Показател } \\
\text { и }\end{array}$ & $\begin{array}{c}\text { ЕР } \\
2007 \\
\text { взвеш. }\end{array}$ & $\begin{array}{c}\text { ЕР } \\
2011 \\
\text { взвеш. }\end{array}$ & $\begin{array}{c}\text { ЕР } \\
2016 \\
\text { взвеш. }\end{array}$ & $\begin{array}{c}\text { ЕР } \\
\text { средне- } \\
\text { взвеш. }\end{array}$ \\
\hline \multicolumn{5}{|c|}{ Татарстан } \\
\hline $\begin{array}{c}\text { Доля } \\
\text { титульных } \\
\text { групп }\end{array}$ & $\begin{array}{c}0,383^{* *} \\
(0,009)\end{array}$ & $\begin{array}{c}0,385^{* *} \\
(0,009)\end{array}$ & $\begin{array}{c}0,368^{*} \\
(0,013)\end{array}$ & $\begin{array}{c}0,397^{* *} \\
(0,007)\end{array}$ \\
\hline $\begin{array}{c}\text { Доля } \\
\text { сельского } \\
\text { населения }\end{array}$ & $\begin{array}{c}0,670^{* *} \\
(0,000)\end{array}$ & $\begin{array}{c}0,714^{* *} \\
(0,000)\end{array}$ & $\begin{array}{c}0,695^{* *} \\
(0,000)\end{array}$ & $\begin{array}{c}0,725^{* *} \\
(0,000)\end{array}$ \\
\hline \multicolumn{5}{|c|}{ Башкортостан } \\
\hline $\begin{array}{c}\text { Доля } \\
\text { титульных }\end{array}$ & $\begin{array}{c}0,225 \\
(0,076)\end{array}$ & $\begin{array}{c}0,184 \\
(0,150)\end{array}$ & $\begin{array}{c}0,218 \\
(0,086)\end{array}$ & $\begin{array}{c}0,245 \\
(0,053)\end{array}$ \\
\hline $\begin{array}{c}\text { Доля } \\
\text { сельского } \\
\text { населения }\end{array}$ & $\begin{array}{c}0,650^{* *} \\
(0,000)\end{array}$ & $\begin{array}{c}0,401^{* *} \\
(0,001)\end{array}$ & $\begin{array}{c}0,382^{* *} \\
(0,002)\end{array}$ & $\begin{array}{c}0,542^{* *} \\
(0,000)\end{array}$ \\
\hline
\end{tabular}

**-корреляция значима на уровне 0,01

(двухсторонняя),

* - корреляция значима на уровне 0,05 (двухсторонняя).

коэффициентов на протяжении всех трех электоральных циклов. В Башкортостане, напротив, значения коэффициентов корреляции между долей титульной группы в населении МО и голосованием за ЕР статистически незначимы на протяжении всего периода. Учитывая вышесказанное о сходстве и различии между республиками, напрашивается вывод, что именно различия в формате локализации титульных этнических групп являются причиной столь разных результатов корреляционного анализа.

Субъекты Российской Федерации невероятно разнообразны как по социальноэкономическим характеристикам, так и в политическом отношении. Хотя «республики» нередко выделяются в особую категорию, исследования показывают, что с точки зрения голосования на федеральных выборах они демонстрируют весьма высокую вариативность. Лояльное по отношению к партии власти голосование связано отнюдь не с «республиканским статусом», а с этнической структурой населения. Будучи этническими по характеру своего конституирования, российские 
республики, разумеется, в целом отличаются по этому параметру от других российских регионов (хотя и здесь обнаруживается значительная вариативность). Значимость этнического фактора в голосовании за партию власти объясняется тем, что «этнические сети» являются важным ресурсом, который используется политическими машинами для электоральной мобилизации. Вместе с тем, как показывает данное исследование, «этнические сети» - это не просто высокая доля представителей этнической группы в составе населения территории. Важным фактором, влияющим на формирование «этнических сетей», является особый - «сегрегирован- ный» формат пространственной локализации этнических групп. Когда члены этнической группы проживают «сегрегировано», то есть обособленно от представителей других этнических групп, возникает значительно больше шансов, что у них возникнут достаточно плотные социальные связи и интенсивные этнические идентичности, которые могут стать инструментом для электоральной мобилизации. Таким образом, гипотеза о том, что формат локализации оказывает существенное влияние на эффект воздействия доли титульной группы в составе населения российских национальных республик, полностью подтверждается.

\section{Библиографический список}

1. Балансируя притязания: этнические региональные автономии, целостность государства и права этнических меньшинств / под ред. П.В. Панова. - М.: Полит. энциклопедия, 2017. - 214 с.

2. Кушнер П.И. Этнические территории и этнические границы. - М.: Изд-во Академии наук CCCP, 1951. - $279 \mathrm{c}$.

3. Минаева Э.Ю. Территориальное измерение сегментации политического пространства на основе картографических проекций в ArcGIS // Цифровая гуманитаристика: ресурсы, методы, исследования: материалы междунар. науч. конф. - Пермь: Перм. гос. нац. исслед. ун-т, 2017. - С. 44-48.

4. Frye T., Reuter O.J., Szakonyi D. Political Machines at Work Voter Mobilization and Electoral Subversion in the Workplace // World Politics. - 2014. - Vol. 66. - № 2. - P. 195-228.

5. Golosov G. Machine Politics: The Concept and Its Implications for Post-Soviet Studies // Demokratizatsiya. - 2013. - Vol. 21. - № 4. - P. 459-480.

6. Hale H. Explaining Machine Politics in Russia's Regions: Economy, Ethnicity, and Legacy // Post-Soviet Affairs. - 2003. - Vol. 19. - № 3. - P. 228-263.

7. Panov P., Ross C. Explanatory Factors for Electoral Turnout in the Russian Federation: The Regional Dimension // Demokratizatsiya: The Journal of Post-Soviet Democratization. - 2016. - Vol. 24. № 3. P. 351-370.

8. Panov P., Ross C. The dynamic nationalisation of voting for United Russia: the stability / instability of regional deviations from national results // East European Politics. - 2018. - Vol. 34. - № 1. - P. 97-114.

9. Panov P., Ross C. Volatility in Electoral Support for United Russia: Cross-Regional Variations in Putin's Electoral Authoritarian Regime // Europe-Asia Studies. - 2019. - Vol. 71. - № 2. - P. 268-289.

10. Scott J. Corruption, Machine Politics, and Political Change // The American Political Science Review. 1969. - Vol. 63. - № 4. - P. 1142-1158.

11. Stokes S. Perverse Accountability: A Formal Model of Machine Politics // American Political Science Review. - 2005. - Vol. 99. - № 3. - P. 315-325.

12. Weidmann N., Rød J., Cederman L.-E. Representing Ethnic Groups in Space: A New Dataset// Journal of Peace Research. - 2010. - № 4. - P. 491-499.

13. Wucherpfennig J., Weidmann N., Girardin L., Cederman L.-E., Wimmer A. Politically Relevant Ethnic Groups across Space and Time: Introducing the GeoEPR Dataset // Conflict Management and Peace Science. - 2011. - № 5. - P. 423-37. 


\title{
ETHNIC GROUPS' SPATIAL LOCALIZATION AS A VOTING FACTOR IN NATIONAL REPUBLICS OF THE RUSSIAN FEDERATION
}

\author{
P.V. Panov \\ Perm Federal Research Centre UB RAS
}

\begin{abstract}
Although «national republics» are identified as a special category of RF units, they demonstrate very high variability of voting in federal elections. In this case, the voting that is loyal to the ruling party is connected not with the «republican status» as it is, but with the ethnic structure of the population in the republics because «ethnic networks» are an important resource used by political machines for electoral mobilization. At the same time, «ethnic networks» are not just high proportion of representatives of an ethnic group in the territory population. An important factor influencing the formation of «ethnic networks» is the format of the spatial localization of ethnic groups. When members of an ethnic group are «segregated», i.e., live separately from members of other ethnic groups, they have a much better chance of sufficiently close social ties and intensive ethnic identities, which can become an instrument of electoral mobilization. This hypothesis has been tested on the empirical data of the State Duma elections in 2007, 2011 and 2016 in national republics. The analysis confirmed that segregation as a special format of spatial localization has a significant influence on the effect of the impact of the titular group proportion in the population of national republics on voting for United Russia.
\end{abstract}

Keywords: national republics, elections, ethnicity, titular group, spatial localization.

\section{Сведения об авторе}

Панов Петр Вячеславович, доктор политических наук, главный научный сотрудник отдела по исследованию политических институтов и процессов, Пермский федеральный исследовательский центр УрО РАН (ПФИЦ УрО РАН), 614990, г. Пермь, ул. Ленина, 13А; e-mail: panov.petr@gmail.com 